\title{
Erratum to: Performance and bacterial communities of successive alkalinity-producing systems (SAPSs) in passive treatment processes treating mine drainages differing in acidity and metal levels
}

Sokhee Philemon Jung • Youngwook Cheong •

Giljae Yim • Sangwoo Ji • Hojeong Kang

Published online: 13 December 2014

(C) Springer-Verlag Berlin Heidelberg 2014

Erratum to: Environ Sci Pollut Res (2014) 21:3722-3732

DOI 10.1007/s11356-013-2366-6

One of the authors would like to have a line in the acknowledgements as:

Acknowledgements: H. Kang is grateful to ERC (2013067218)'.

It was not included in the original paper by mistake.

The online version of the original article can be found at http://dx.doi.org/ 10.1007/s11356-013-2366-6.

S. P. Jung $(\bowtie) \cdot H$. Kang $(\bowtie)$

School of Civil and Environmental Engineering, Yonsei University,

Seoul, South Korea

e-mail: sokheejung@gmail.com

e-mail: hj_kang@yonsei.ac.kr

Y. Cheong $\cdot$ G. Yim $\cdot$ S. Ji $(\bowtie)$

Korea Institute of Geoscience and Mineral Resources (KIGAM),

Daejeon, South Korea

e-mail: swji@kigam.re.kr 